\title{
Effects of Co-Administration of Monomethylaminoantipyrine and Cobaltous Chloride on Hepatic Glutathione Level and Glutathione-Related Enzyme Activities in Rats
}

\author{
Katsuji HOSHI, Naoto SENDA, Takashi IGARASHI*, \\ Tetsuo SATOH**, Koichi UENO* and Haruo KITAGAWA* \\ Department of Pharmacology. Hokkaido Institute of Pharmaceutical Sciences, \\ 7-1 Katsuraoka-cho, Otaru 047-02, Japan \\ *Laboratory of Biochemical Pharmacology and Biotoxicology, \\ Faculty of Pharmaceutical Sciences, Chiba University. \\ 1-33 Yayoi-cho, Chiba 260. Japan \\ **Department of Pharmacology and Toxicology. Tokyo College of Pharmacy, \\ 1432-1 Horinouchi. Hachioji. Tokyo 192-03, Japan
}

Accepted December 22, 1986

\begin{abstract}
Concurrent administration of monomethylaminoantipyrine (MAA) and $\mathrm{COCl}_{2}$ caused a significant decrease of hepatic reduced glutathione and oxidized glutathione levels. Furthermore, the increase of glutathione S-transferase activity by combined treatment resulted in the decrease of Se-dependent glutathione peroxidase activity.
\end{abstract}

We previously reported that treatment of rats with MAA caused a significant increase of hepatic gamma-glutamyltranspeptidase $(\gamma$ GTP) activity (1). Later, we revealed that coadministration of MAA and $\mathrm{COCl}_{2}$ enhanced the MAA-induced increase of hepatic $\gamma$ GTP activity in rats (2). Such a marked increase of hepatic $\gamma$-GTP by co-administration of $\mathrm{MAA}$ and $\mathrm{CoCl}_{2}$ is thought to change glutathione level and related enzymatic activity.

The present study was therefore designed to investigate the effect of $\mathrm{CoCl}_{2}$ alone and in combination with MAA on glutathione level and glutathione-related enzymes in rat liver.

\section{Materials and Methods}

Animals and drug administration: Male Sprague-Dawley rats weighing 140 to $150 \mathrm{~g}$ were used. They were housed in groups of 3 animals on wire-bottomed stainless steel cages and freely given water and commercial laboratory chow CE-2 (Clea Japan Inc., Tokyo, Japan). A 6:00 a.m.-6:00 p.m. light cycle was maintained. Rats were divided into four groups. The first group received oral administration of $5 \%$ gum arabic solution as a control. The second group received oral administration of MAA $(563.7 \mathrm{mg} / \mathrm{kg}$. equimolar to $600 \mathrm{mg} / \mathrm{kg}$ of aminopyrine) for 3 consecutive days. The third and fourth groups received $\mathrm{CoCl}_{2}$ alone $(20 \mathrm{mg} / \mathrm{kg}$. subcutaneously) and in combination with MAA ( $563.7 \mathrm{mg} / \mathrm{kg}$ ) for 3 consecutive days, respectively. $\mathrm{CoCl}_{2}$ was administered to rats $2 \mathrm{hr}$ prior to MAA administration. Animals were killed at 9:00 a.m. to 10:00 a.m. Animals were sacrificed by decapitation $24 \mathrm{hr}$ after the last administration of MAA, and the hepatic homogenate and cytosolic fractions were prepared as reported previously (1).

Chemicals: $\gamma$-Glutamyl-p-nitroanilide, GSH and GSSG were purchased from Sigma Chemical Co., St. Louis, MO, U.S.A. $\mathrm{CoCl}_{2}$, glycylglycine, p-dimethylaminocinnamaldehyde, 1-chloro-2,4-dinitrobenzene and tris (hydroxymethyl)aminomethane were from Wako Pure Chemical Industries, Ltd., Tokyo, Japan. MAA was prepared according to the method of Morita (3). Other reagents were of analytical grade.

Assay methods: Individual contents of reduced glutathione (GSH) and oxidized 
glutathione (GSSG) were measured by the fluorescence assay procedure of Hissin and Hilf (4). Glutathione (GSH) S-transferase activity was measured with 1-chloro-2,4dinitrobenzene $(340 \mathrm{~nm})$ as a substrate. according to Habig et al. (5). Glutathione peroxidase activity of the cytosol was measured spectrophotometrically by the procedure of Reddy et al. (6). Glutathione reductase activity was measured by the method of Massey and Williams (7). $r$-GTP activity of rat serum was measured by the method of Igarashi et al. (8). The activities of glutamate oxaloacetate transaminase (GOT) and glutamate pyruvate transaminase (GPT) were determined by using the commercial reagent kits of latron Co., Ltd., Tokyo, Japan $(9,10)$. Protein concentration was determined by the method of Lowry et al. (11).

Student's $t$-test was used to establish significant differences in mean values between the control and treated groups. The data were subjected to $2 \times 2$ factorial analysis of variance.

\section{Results}

Effects of MAA alone and in combination with $\mathrm{CoCl}_{2}$ on the weights of body and liver, on the activities of serum $\gamma$-GTP, GPT and GOT, and on the amounts of water and food intakes: As shown in Table 1, repeated administration of $\mathrm{CoCl}_{2}$ alone or MAA and $\mathrm{COCl}_{2}$ for 3 days significantly decreased the body weight. Moreover, administration of MAA alone caused an increase in the liver weight. while administration of $\mathrm{CoCl}_{2}$ alone led to a decrease. On the other hand, simultaneous administration of $\mathrm{MAA}$ and $\mathrm{COCl}_{2}$ resulted in a significant increase of serum $r$-GTP and GOT activities when compared to the control, but not in GPT activity. In addition, repeated administration of $\mathrm{CoCl}_{2}$ alone for 3 days resulted in a significant decrease in the amounts of water and food intakes when compared with the control, but the amounts of these intakes remained unchanged after treatment with MAA alone. Moreover, a significant decrease of the amount of food intake was observed by combined adminis tration of MAA and $\mathrm{CoCl}_{2}$.

Effects of MAA alone and in combination with $\mathrm{CoCl}_{2}$ on hepatic glutathione levels of rat liver: Table 2 indicates the changes in GSH and GSSG levels of rat liver after administration of either MAA or $\mathrm{CoCl}_{2}$ alone and combined administration of both drugs. The GSH and GSSG levels remained unchanged after treatment with $\mathrm{MAA}$ or $\mathrm{COCl}_{2}$ alone. However. a significant decreases of GSH and GSSG levels were observed by combined administration of MAA and $\mathrm{CoCl}_{2}$.

Effects of MAA alone and in combination with $\mathrm{CoCl}_{2}$ on the activities of GSH Stransferase and GSSG reductase: As shown in Table 3. a single administration of MAA or $\mathrm{CoCl}_{2}$ resulted in the increase of $\mathrm{GSH}$ Stransferase activity. Moreover, combined administration of MAA and $\mathrm{COCl}_{2}$ caused a marked increase of GSH S-transferase activity. On the other hand, treatment of rats with MAA or $\mathrm{CoCl}_{2}$ alone caused a significant increase in GSSG reductase activity. Furthermore, co-administration of MAA and $\mathrm{CoCl}_{2}$ also increased the activity of GSSG reductase (Table 3).

Effects of MAA alone and in combination with $\mathrm{CoCl}_{2}$ on the activities of glutathione peroxidase: Table 4 shows the effect of a single administration of MAA or $\mathrm{CoCl}_{2}$ and combined administration of both drugs on glutathione peroxidase activities of rat liver. Glutathione peroxidase activity with $\mathrm{H}_{2} \mathrm{O}_{2}$ as a substrate was significantly decreased by combined treatment. However, the activity towards cumene hydroperoxide was not changed.

\section{Discussion}

The previous paper (2) demonstrated that the induction of hepatic $r$-GTP by MAA treatment was remarkably enhanced by pretreatment with $\mathrm{CoCl}_{2}$, by which hepatic microsomal drug metabolism and microsomal content of cytochrome P-450 were diminished.

Prohaska and Ganther (12) reported that the selenium-independent GSH peroxidase (non-Se GSH-PX) activity was associated with the GSH S-transferase and with both the $Y_{a}$ and $Y_{c}$ monomers in the $B_{1}$ and $B_{2}$ forms of the transferase $(13,14)$. On the other hand, selenium-dependent GSH peroxidase (Se GSH-Px) activity also is mainly present in the cytosol (6), and GSH-PX appeared to 


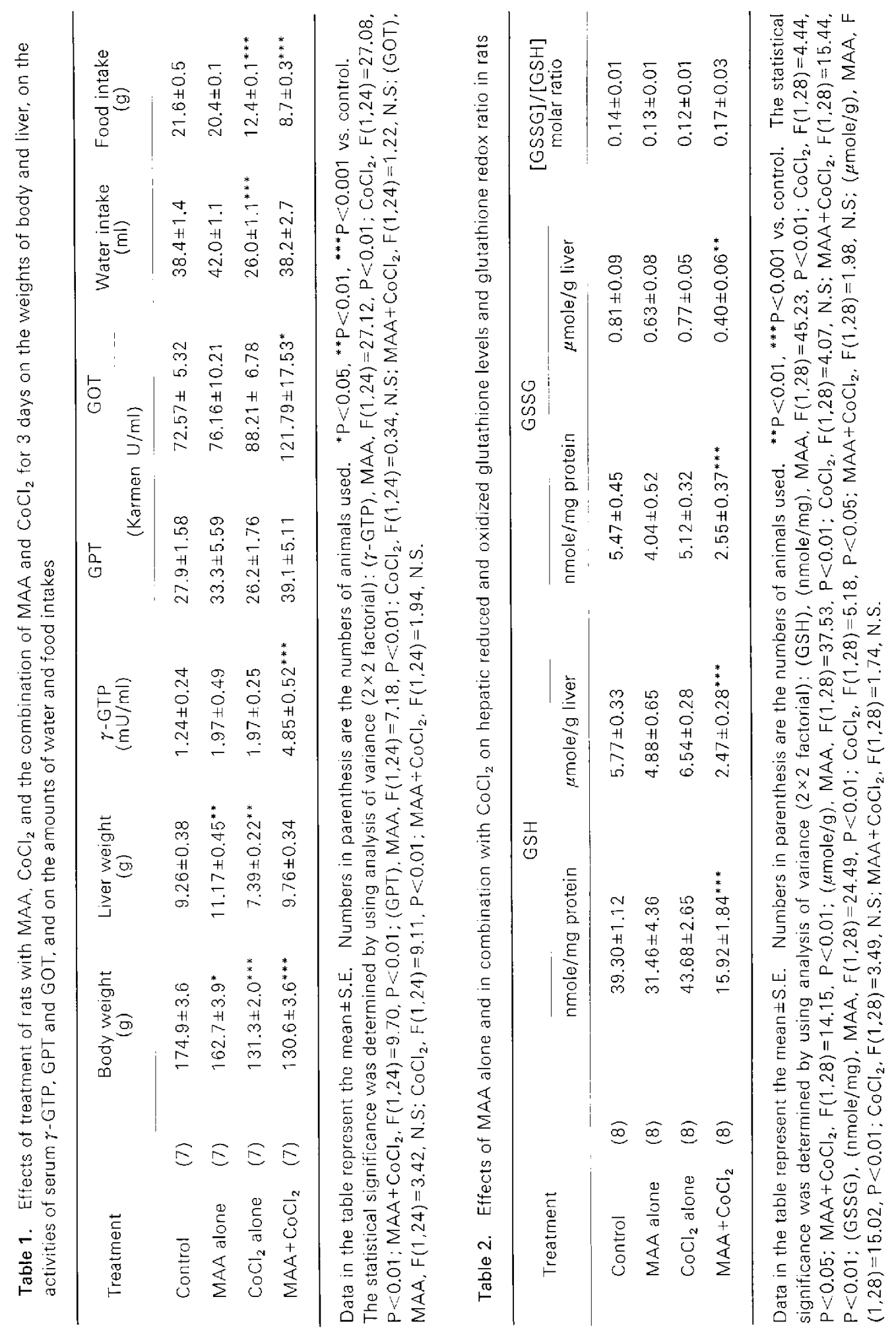


Table 3. Effects of MAA alone and in combination with $\mathrm{CoCl}_{2}$ on the activities of glutathione S-transferase and glutathione reductase in rat liver

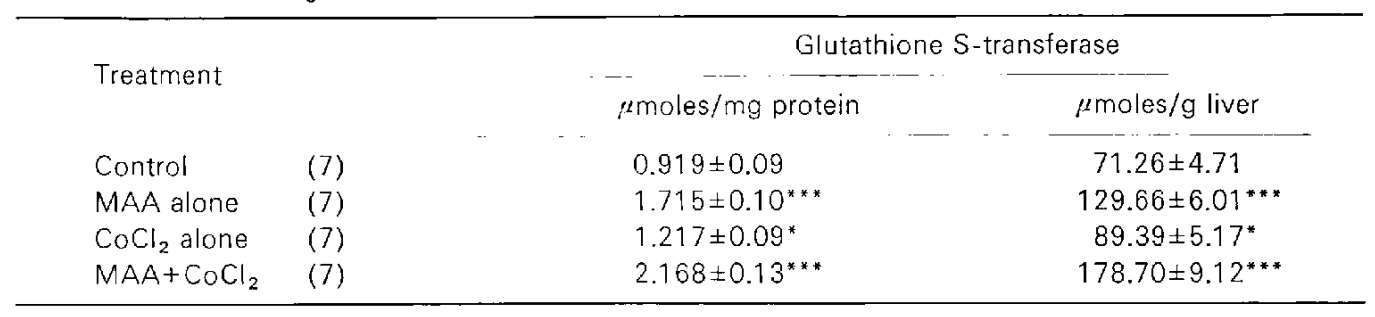

Treatment

Control

MAA alone

$\mathrm{COCl}_{2}$ alone

$\mathrm{MAA}+\mathrm{CoCl}_{2}$
(8)
Glutathione (GSSG) reductase

$\begin{array}{cc}\text { nmoles/mg protein } & \mu \text { moles/g liver } \\ 50.94 \pm 7.99 & 3.98 \pm 0.62 \\ 146.61 \pm 12.25^{* * *} & 11.06 \pm 0.91^{* *} \\ 119.34 \pm 11.69^{* * *} & 9.51 \pm 0.92^{* *} \\ 141.36 \pm 16.27^{* *} & 11.69 \pm 1.38^{* *}\end{array}$

Data in the table represent the mean \pm S.E. Numbers in parenthesis are the numbers of animals used. ${ }^{*} \mathrm{P}<0.05,{ }^{* *} \mathrm{P}<0.001$ vs. control. The statistical significance was determined by using analysis of variance $\left(2 \times 2\right.$ factorial): (GSH S-transferase), ( $\mu$ moles/mg), $\mathrm{MAA}, \mathrm{F}(1,24)=72.91, \mathrm{P}<0.01 ; \mathrm{CoCl}_{2}$,

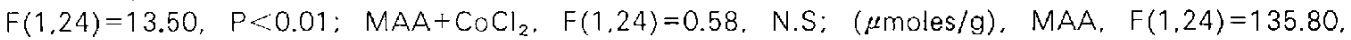
$P<0.01 ; \mathrm{CoCl}_{2}, \mathrm{~F}(1,24)=28.08, \quad \mathrm{P}<0.01 ; \mathrm{MAA}+\mathrm{CoCl}_{2}, \mathrm{~F}(1,24)=5.95, \mathrm{~N} . \mathrm{S} ; \quad$ (GSSG reductase); (nmoles/mg), MAA, F(1.28)=27.76, P<0.01: $\mathrm{CoCl}_{2}, \mathrm{~F}(1.28)=7.99, \mathrm{P}<0.01 ; \mathrm{MAA}+\mathrm{CoCl}, \mathrm{F}(1,28)$ $=10.87, \mathrm{P}<0.01 ;(\mu$ moles $/ g), \mathrm{MAA}, \mathrm{F}(1,28)=26.91, \mathrm{P}<0.01: \mathrm{CoCl}_{2}, \mathrm{~F}(1,28)=11.90, \mathrm{P}<0.01: \mathrm{MAA}+$ $\mathrm{CoCl}_{2}, \mathrm{~F}(1,28)=7.55, \mathrm{P}<0.05$.

Table 4. Effects of MAA alone and in combination with $\mathrm{CoCl}_{2}$ on hepatic glutathione peroxidase activities in rat liver

\begin{tabular}{|c|c|c|c|c|c|}
\hline \multirow{3}{*}{ Treatment } & & \multicolumn{4}{|c|}{ Glutathione peroxidase } \\
\hline & & \multicolumn{2}{|c|}{ Hydrogen peroxide $(0.25 \mathrm{mM})$} & \multicolumn{2}{|c|}{ Cumene hydroperoxide $(1.2 \mathrm{mM})$} \\
\hline & & $\begin{array}{l}\mu \text { moles } / \text { min/ } \\
\text { mg protein }\end{array}$ & $\begin{array}{l}\mu \text { moles/min/ } \\
\mathrm{g} \text { liver }\end{array}$ & $\begin{array}{l}\mu \text { moles/min/ } \\
\text { mg protein }\end{array}$ & $\begin{array}{l}\mu \text { moles } / \mathrm{min} / \\
\mathrm{g} \text { liver }\end{array}$ \\
\hline Control & (8) & $0.288 \pm 0.03$ & $22.46 \pm 1.79$ & $0.440 \pm 0.02$ & $34.73 \pm 2.23$ \\
\hline MAA alone & (8) & $0.245 \pm 0.01$ & $18.43 \pm 0.85$ & $0.489 \pm 0.02$ & $37.06 \pm 2.00$ \\
\hline $\mathrm{CoCl}_{2}$ alone & (8) & $0.274 \pm 0.03$ & $24.76 \pm 3.01$ & $0.482 \pm 0.04$ & $38.29 \pm 2.40$ \\
\hline $\mathrm{MAA}+\mathrm{CoCl}_{2}$ & (8) & $0.198 \pm 0.01^{* *}$ & $16.39 \pm 0.95^{*}$ & $0.450 \pm 0.02$ & $37.23 \pm 1.59$ \\
\hline
\end{tabular}

Data in the table represent the mean + S.E. Numbers in parenthesis are the numbers of animals used. ${ }^{*} \mathrm{P}<0.05,{ }^{*} \mathrm{P}<0.01 \mathrm{vs}$. control. The statistical significance was determined by using analysis af variance

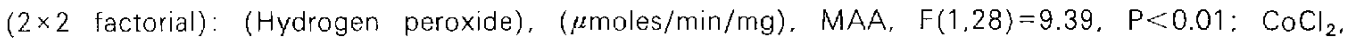

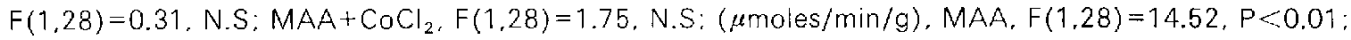
$\mathrm{CoCl}_{2}, \mathrm{~F}(1,28)=0.01$. N.S: $\mathrm{MAA}+\mathrm{CoCl}_{2} . \mathrm{F}(1,28)=1.78$. N.S: (Cumene hydroperoxide). ( $\mu \mathrm{moles} / \mathrm{min} /$ mg), MAA, $F(1,28)=0.41, N . S ; \mathrm{CoCl}_{2}, \mathrm{~F}(1,28)=0.01, \mathrm{~N} . \mathrm{S} ; \mathrm{MAA}+\mathrm{CoCl}_{2}, \mathrm{~F}(1.28)=3.45$, N.S; (/mmoles/ $\mathrm{min} / \mathrm{g})$. MAA, $F(1,28)=0.12$, N.S; $\mathrm{CoCl}_{2}, F(1,28)=1.00$. N.S; $\mathrm{MAA}+\mathrm{CoCl}_{2}, \mathrm{~F}(1,28)=0.83$, N.S.

play a major role in the decomposition of $\mathrm{H}_{2} \mathrm{O}_{2}$ formed in the cytosol (15). As shown in Tables 3 and 4 , the increase of GSH Stransferase activity by combined administration of MAA and $\mathrm{CoCl}_{2}$ resulted in a decrease of the Se-dependent GSH-PX activity, but not the Se-independent one. Our results may indicate that generation of $\mathrm{H}_{2} \mathrm{O}_{2}$ during cytochrome $\mathrm{P}$-450-mediated drug oxidation is relatively poor. This can be partly explained by the relative degradation of the hepatic Se-dependent GSH-Px activity 
which, in turn, caused a decrease of GSSG content. and concomitant increases in the activities of GSH S-transferase and GSSG reductase were observed.

Combined administration of MAA and $\mathrm{CoCl}_{2}$ also caused a marked increase of serum $r$-GTP activity, but no significant increase in hepatic GPT activity was observed (Table 1). Serum $\gamma$-GTP originates from liver (16), and glutathione contents in the liver is modulated by $r$-GTP which is the only known enzyme capable of cleaving the $\gamma$-glutamyl bond of GSH and GSSG possessing a $\gamma$ glutamyl moiety.

As shown in Table 2, combined administration of $\mathrm{MAA}$ and $\mathrm{CoCl}_{2}$ decreased $\mathrm{GSH}$ and GSSG contents. Furthermore, Table 1 shows a significant decrease of the body weight and decreased amount of food intake when MAA plus $\mathrm{CoCl}_{2}$ was administered to rats. Tateishi et al. (17) reported that glutathione level in the liver is closely related to nutritional conditions. In these experiments. the depletion of hepatic GSH and GSSG appears to be partly due to the insufficient food intake in rats.

\section{References}

1 Hoshi, K., Senda, N., Igarashi, T., Satoh, T., Ueno, K. and Kitagawa, $H$. : Effect of repeated administration of monomethylaminoantipyrine on the activities of $\gamma$-glutamyltranspeptidase and microsomal drug metabolizing enzymes in rat Iiver. Res. Commun. Chem. Pathol. Pharmacol. 48, 431-443 (1985)

2 Hoshi, K., Senda, N., Igarashi, T., Satoh, T., Ueno, K. and Kitagawa, H.: Enhancement of monomethylaminoantipyrine-induced increase of hepatic gamma-glutamyltranspeptidase activity by cobaltous chloride in rats. Res. Commun. Chem. Pathol. Pharmacol. 51, 81-88 (1986)

3 Morita, M.: Synthesis and antibacterial activity of antipyrine derivatives. III. Decomposition and colorimetric determination of sulpyrine. Yakugaku Zasshi. 82, 50-56 (1962) (in Japanese)

4 Hissin, P.J. and Hilf, R.: A fluorometric method for determination of oxidized and reduced glutathione in tissues. Anal. Biochem. 74, 214226 (1976)

5 Habig, W.H., Pabst, M.J. and Jakoby, W.B.: Glutathione $S$-transferase. The first enzymatic step in mercapturic acid formation J. Biol. Chem. 249, 7130-7139 (1974)

6 Reddy, C.C., Tu, C.-P.D., Burgess, J.R., Ho, C. -Y., Scholz, R.W. and Massaro, E.J.: Evidence for the occurrence of selenium-independent glutathione peroxidase activity in rat liver microsomes. Biochem. Biophys. Res. Commun. 101, 970-978 (1981)

7 Massey, $V$, and Williams, C.H.: On the reaction mechanism of yeast glutathione reductase. J. Biol. Chem. 240, 4470-4480 (1965)

8 Igarashi, T., Satoh, T., Ueno, K. and Kitagawa, $H$.: Sex-related dfferences in the hepatic glutathione level and related enzyme activities in rat. J. Biochem. 93, 33-36 (1983)

9 Karmen, A.: A note on the spectrophotometric assay of glutamic oxalacetic transaminase in human blood. J. Clin. Invest. 34, 131-133 (1955)

10 Wróblewski, F. and LaDue, J.S.: Serum glutamic pyruvic transaminase in cardiac and hepatic disease. Proc. Soc. Exp. Biol. Med. 91, 569-571 (1956)

11 Lowry, O.H., Rosebrough, N.J., Farr, A.L. and Randall, R.J.: Protein measurement with the Folin phenol reagent. J. Biol. Chem. 193, 265275 (1951)

12 Prohaska, J.R. and Ganther, H.E.: Glutathione peroxidase activity of glutathione-S-transferase purified from rat Iiver. Biochem. Biophys. Res. Commun. 76, 437-445 (1977)

13 Ketterer, B., Beale, D. and Meyer, D.: The structure and multiple functions of glutathione transferase. Biochem. Soc. Trans. 10, 82-84 (1982)

14 Mehlert, A. and Diplock, A.T.: The glutathione S-transferase in selenium and vitamin $E$ deficiency. Biochem. J. 227, 823-831 (1985)

15 Eklöw, L., Moldéus, P. and Orrenius, S.: Oxidation of glutathione during hydroperoxide metabolism. A study using isolated hepatocytes and the glutathione reductase inhibitor 1,3-bis(2-chioroethyl)-1-nitrosourea. Eur. J. Biochem. 138, 459-463 (1984)

16 Teschke, R., Brand, A, and Strohmeyer, G.: Induction of hepatic microsomal gammaglutamyltransferase activity following chronic alcohol consumption. Biochem. Biophys. Res. Commun. 75, 718-724 (1977)

17 Tateishi, N., Higashi, T., Shinya, S., Naruse, A. and Sakamoto, $Y$ :: Studies on the regulation of glutathione level in rat liver. J. Biochem. 75, 93-103 (1974) 